\title{
Interfacial Charge-transfer Doping of Metal Halide Perovskites for
}

\section{High Performance Photovoltaics}

Nakita K. Noel,${ }^{1,2^{*}}$ Severin N. Habisreutinger, ${ }^{3}$ Alba Pellaroque, ${ }^{4}$ Federico Pulvirenti, ${ }^{5}$ Bernard Wenger, ${ }^{4}$ Fengyu Zhang, ${ }^{1}$ Yen-Hung Lin, ${ }^{4}$ Obadiah G. Reid, ${ }^{3,6}$ Johannes Leisen, ${ }^{5}$ Yadong Zhang, ${ }^{5}$ Stephen Barlow, ${ }^{5}$ Seth R. Marder, ${ }^{5}$ Antoine Kahn, ${ }^{1}$ Henry J. Snaith, ${ }^{4}$ Craig B. Arnold, ${ }^{2}$ Barry P. $\operatorname{Rand}^{1,7 *}$

${ }^{1}$ Department of Electrical Engineering, Princeton University, Princeton, NJ, 08544, USA.

${ }^{2}$ Princeton Research Institute for the Science and Technology of Materials, Princeton University, Princeton, NJ, 08544, USA.

${ }^{3}$ National Renewable Energy Laboratory, 15013 Denver West Parkway, Golden, Colorado, 80401, USA.

${ }^{4}$ Clarendon Laboratory, Department of Physics, University of Oxford, Parks Road, Oxford, OX1 3PU, UK.

${ }^{5}$ School of Chemistry and Biochemistry and Center for Organic Photonics and Electronics, Georgia Institute of Technology, Atlanta, Georgia 30332-0400, USA.

${ }^{6}$ Renewable and Sustainable Energy Institute, University of Colorado at Boulder, Boulder, CO 80309, USA

${ }^{7}$ Andlinger Center for Energy and the Environment, Princeton University, Princeton, NJ, 08544, USA.

*Corresponding Authors: nnoel@princeton.edu, brand@princeton.edu 


\section{Abstract:}

The remarkable optoelectronic properties of metal halide perovskites have generated intense research interest over the last few years. The ability to control and manipulate the crystallisation and stoichiometry of perovskite thin-films has allowed for impressive strides in the development of highly efficient perovskite solar cells. However, being able to effectively modify the interfaces of metal halide perovskites, and to controllably p or n-type dope the surfaces, may be key to further improvements in the efficiency and long-term stability of these devices. In this study, we use surface doping of the mixed-cation, mixed-halide perovskite $\mathrm{FA}_{0.85} \mathrm{MA}_{0.15} \mathrm{~Pb}\left(\mathrm{I}_{0.85} \mathrm{Br}_{0.15}\right)_{3}$ (FA formamidinium; MA - methylammonium) to improve the hole extraction from the perovskite solar cell. By treating the surface of the perovskite film with a strongly oxidizing molybdenum tris(dithiolene) complex, we achieve a shift in the work function that is indicative of p-doping, and a twofold increase in the total conductivity throughout the film. We probe the associated interfacial chemistry through photoelectron and solid-state nuclear magnetic resonance spectroscopies and confirm that charge-transfer occurs between the perovskite and dopant complex. The resulting pdoped interface constitutes a homojunction with increased hole-selectivity. With charge-selective layers, we show that this surface doping enhances the device performance of perovskite solar cells resulting in steady-state efficiencies approaching $21 \%$. Finally, we demonstrate that a surface treatment with this dopant produces the same effect as the commonly employed additive 4-tert butylpyridine ( $t \mathrm{BP})$, allowing us to achieve " $t \mathrm{BP}$-free" devices with steady-state efficiencies of over $20 \%$, and enhanced thermal stability as compared to devices processed using $t \mathrm{BP}$. Our findings therefore demonstrate that molecular doping is a feasible route to tune and control the surface properties of metal halide perovskites.

\section{Introduction:}


Metal halide perovskites are fast becoming ubiquitous in optoelectronics research. While these materials have demonstrated applications in light emitting diodes (LEDs) ${ }^{1,2}$ and lasers, ${ }^{3,4}$ they are currently most well-known for their use in high efficiency photovoltaics, ${ }^{5,6}$ and have been hailed materials which have the potential to significantly contribute to providing clean, inexpensive energy sources. ${ }^{7}$ To date, metal halide perovskites have been used most extensively as active layers in photovoltaic devices. The power conversion efficiencies (PCEs) of these devices have soared from $3.8 \%$ at their inception, ${ }^{8}$ to step over $10 \%$ in $2012,{ }^{5,6}$ and to certified values of over $23 \%$ just six years later, placing perovskite-based solar cells at the vanguard of emerging photovoltaic technologies. ${ }^{9}$

This rapid progress is largely a result of the large absorption coefficients, high electron and hole mobilities, low exciton binding energies, and long range ambipolar charge transport in metal halide perovskites. ${ }^{6,10-12}$ Additionally, tremendous effort has been placed on managing and tuning the crystallisation and composition of bulk perovskite films, controlling their stoichiometry, and surface passivation of the crystallised material, all contributing to improvements in the reproducibility and efficiency of perovskite-based devices. ${ }^{13-19}$ The excellent electronic properties of metal halide perovskite absorbers are a consequence of the serendipitous overlap of the electronic orbitals of the lead and the halogen atoms, which energetically places most bulk defects within the energy bands of these semiconductors. ${ }^{20}$ Consequently, most relevant defects are located at the grain boundaries and interfaces of the absorber layer. Indeed, studies by Zarazua et al., have pointed towards interfacial recombination being one of the main loss mechanisms in perovskite photovoltaics. ${ }^{21,22}$ Eliminating surface defects (which are typically the result of discontinuities in the crystal structure, resulting in lattice vacancies, interstitial species or 
undercoordinated ions ${ }^{23}$ ) can, therefore, be one of the most effective methods for improving the performance and stability of perovskite solar cells. This is typically done through the modification of the interfaces between the perovskite and charge-selective layers, which effectively reduces surface recombination, enhancing charge extraction, reducing hysteresis, and improving device stability. ${ }^{23-28}$

Thus far, most interface modifications in perovskite solar cells can be divided into two main categories: surface passivation of the perovskite material, and improvements to the chargetransport layers. Surface passivation has primarily been shown to reduce non-radiative recombination by decreasing the defect density of the perovskite film, ${ }^{29}$ and in some cases, even improves the environmental stability of the material. ${ }^{30}$ Common surface treatments include Lewis bases (such as pyridine and thiophene), and alkylammonium halides, such as methylammonium chloride $(\mathrm{MACl})$ and choline chloride $(\mathrm{ChCl}) .{ }^{17,31-33}$ Modification of charge transport layers has been carried out using various approaches, all with the same overarching goals: reducing interfacial recombination and improving device stability. Judicious choice of the hole and electron transport materials, such that band alignment with the perovskite material is improved, has previously been shown to improve the performance of perovskite photovoltaics. ${ }^{27,34-36}$ A reduction in the interfacial recombination has also been achieved through the inclusion of buffer layers between the perovskite and charge transport layers. ${ }^{37-39}$ Specifically in the case of metal oxide transport layers, this is thought to occur through the suppression of chemical reactions between the two materials, and through the passivation of defect states in the oxide. ${ }^{23}$ The introduction of a buffer, or interlayer could also be considered as a passivation to the surface of the perovskite film itself. Additionally, charge transport layers have been modified via doping with the aim of 
increasing the conductivity of these layers, or through the introduction of an electrode work function modifier, both of which ultimately act to improve charge extraction in the device. ${ }^{25,26,40,41}$

4-tert-Butylpyridine $(t \mathrm{BP})$ is a common additive to one of the most widely used hole transport materials (HTMs) 2,2',7,7'-tetrakis[N,N-di(4-methoxyphenyl)amino]-9,9'-spirobifluorene (spiroOMeTAD), and is used in most highly efficient (n-i-p) perovskite solar cells. Habisreutinger and co-workers have previously investigated the mechanistic role of $t \mathrm{BP}$ in perovskite solar cells, and found that it directly interacts with the perovskite surface, resulting in improved hole selectivity at the perovskite/spiro-OMeTAD interface. ${ }^{42}$ The improved selectivity at this interface led to increased open-circuit voltages $\left(V_{O C}\right)$ (presumably due to reduced electron-hole recombination at the heterojunction), higher fill factors $(F F)$ and, most importantly, better device performance under operating conditions. This finding suggests that the use of $t \mathrm{BP}$ induces a chemical modification of the perovskite interface that is important for field-independent charge extraction in perovskite solar cells. Such an effect is consistent with the formation of a homojunction at the interface of the perovskite absorber where changes in the band energetics improve the charge extraction while also reducing charge recombination.

Efficient perovskite solar cells require charge selective contacts with appropriately aligned energy levels, such that they facilitate extraction of electrons/holes while blocking charges of the opposite polarity. One possible strategy to further reduce interface recombination is to locally dope perovskite interfaces, akin to traditional inorganic solar cells. However, the science of doping is not currently well-established for metal-halide perovskites. Many attempts have been made to dope 
these materials with extrinsic ions, with varying degrees of success. ${ }^{43-47}$ While in some cases ions have been shown to be incorporated into the perovskite material, reports of changes in the density of free carriers in the host are rare. However, there are reports of substrate dependent doping density in these materials, where the p- or n-type character of the material can be modulated by varying the nature of the substrate upon which it is crystallised, ${ }^{48}$ and of varying the doping density through manipulating the perovskite stoichiometry. ${ }^{49}$ A recent study by Cui et al. reports the fabrication of a photovoltaic device where the doping density of the perovskite is modulated by stacking layers in which the perovskite stoichiometry is varied slightly. ${ }^{50}$ An n-type perovskite is produced through crystallisation of the perovskite on $\mathrm{TiO}_{2}$, after which a layer of p-type perovskite is deposited through thermal evaporation of $\mathrm{PbI}_{2}$ and a subsequent treatment of methylammonium iodide in isopropanol. This appears to create a homojunction in the perovskite layer which, the authors posit allows for reduced recombination through the establishment of a built-in field. It is unclear however, given the propensity of perovskite films to undergo ion redistribution and homogenisation under light and bias, how stable such a system would be under operating conditions. Indeed, the unlikelihood of the operational stability of such a system has recently been expounded upon by Calado and Barnes. ${ }^{51}$

Here, we explore the feasibility of molecular p-doping of the perovskite surface. To do this, we employ the two one-electron molybdenum tris(dithiolene) $\left(\mathrm{Mo}(\mathrm{dt})_{3}\right)$ oxidants, (molybdenum tris(1-(trifluoroethanoyl)-2-(trifluoromethyl)ethane-1,2-dithiolene) and molybdenum tris(1(methoxycarbonyl)-2- (trifluoromethyl)ethane-1,2-dithiolene), which we have previously shown to be effective p-dopants of spiro-OMeTAD in lieu of the hygroscopic lithium bis((trifluomethyl)sulfonyl) imide (Li-TFSI). ${ }^{41}$ Not only are these dopants strong oxidising agents, 
but they are sufficiently large to inhibit migration into the bulk material. Through a series of spectroscopic and device-based experiments, we present evidence that the dopant-treated interface does indeed become more p-type due to electron-transfer between the perovskite and the Mo(dt) 3 complexes. This surface doping results in improved device performance and long-term thermal stability.

\section{Results and Discussion:}
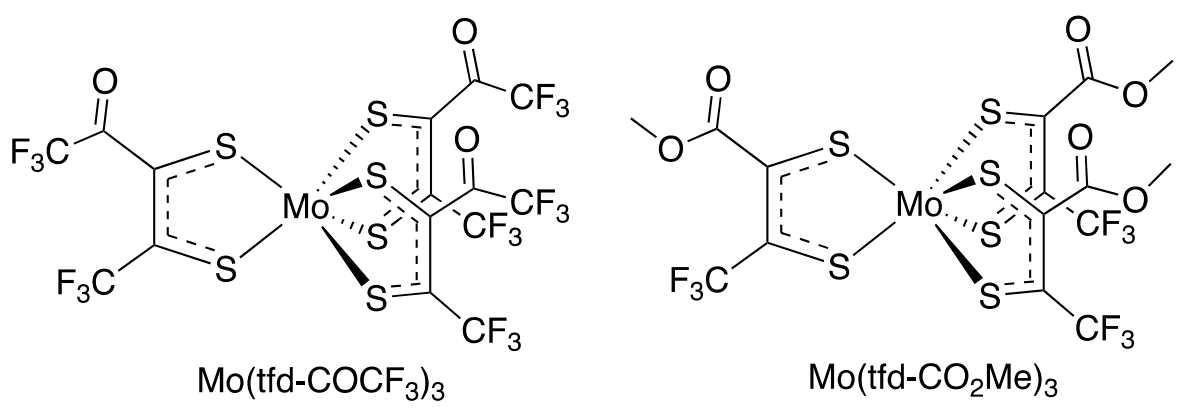

Figure 1. Chemical structures of $\mathrm{Mo}\left(\mathrm{tfd}-\mathrm{COCF}_{3}\right)_{3}$ and $\mathrm{Mo}\left(\mathrm{tfd}-\mathrm{CO}_{2} \mathrm{Me}_{3}\right)_{3}$.

In this study, we mainly focus on $\mathrm{Mo}\left(\mathrm{tfd}-\mathrm{COCF}_{3}\right)_{3}$, which is the more oxidizing of the two soluble $\mathrm{Mo}(\mathrm{dt})_{3}$ dopant systems considered. We show the chemical structures of $\mathrm{Mo}\left(\mathrm{tfd}-\mathrm{COCF}_{3}\right)_{3}$ and $\mathrm{Mo}\left(\mathrm{tfd}-\mathrm{CO}_{2} \mathrm{Me}\right)_{3}$ in Figure 1. Firstly, we investigate whether treating the surface of the perovskite with various concentrations of the Mo-dopant significantly changes the chemical composition of a mixed cation, mixed halide, $\mathrm{FA}_{0.85} \mathrm{MA}_{0.15} \mathrm{~Pb}\left(\mathrm{I}_{0.85} \mathrm{Br}_{0.15}\right)_{3}$ perovskite film. To do this we treat perovskite films, via spin-coating, with solutions of $\mathrm{Mo}\left(\mathrm{tfd}-\mathrm{COCF}_{3}\right)_{3}$ in chlorobenzene at various concentrations and perform UV-Vis absorption and X-ray diffraction (XRD) measurements. We present the results in Figures S1 and S2, respectively. From the absorption spectra, we observe no 
discernible change between the absorption onsets of the neat and treated perovskite films, suggesting that the chemical composition of the film remains largely unchanged when treated with a 1.0 wt.\% solution of the dopant. This is further corroborated by XRD (Fig. S2) which shows that surface treatment of the films with dilute dopant solutions produces no change in the perovskite crystal structure. These results suggest that the dopant molecules remain at the surface or grain boundaries of the film and are not incorporated into the bulk material. We note here, that for these and all subsequent experiments presented, the control samples have been treated with chlorobenzene and undergone an equivalent post-annealing step to rule out any solvent and/or annealing related effects.

Having determined that treating the perovskite film surface with a dilute solution of the Mo(tfd$\left.\mathrm{COCF}_{3}\right)_{3}$ dopant neither alters the crystal structure nor the chemical composition of the material, we investigate the effect of this treatment on the morphology of the films. Figure $\mathbf{S 3}$ shows topview scanning electron microscope (SEM) images of neat and dopant-treated films. We observe no significant changes to the surface morphology of the films when they are treated with very dilute dopant solutions. However, at a concentration of $0.1 \mathrm{wt} \%$, small, yet distinct particles are visible on the surface of the perovskite film. The density of these particles increases upon treatment with a 1.0 wt. $\%$ solution of the dopant. The formation of these dopant clusters on the surface of the perovskite film is likely due to the limited solubility of $\mathrm{Mo}\left(\mathrm{tfd}-\mathrm{COCF}_{3}\right)_{3}$ in chlorobenzene. The presence of unreacted dopant is further confirmed through solid-state NMR measurements, discussed below. At a concentration of $1 \mathrm{wt} . \%$, the dopant solution is very near to its solubility limit, resulting in the formation of a rough and non-uniform film upon deposition. 

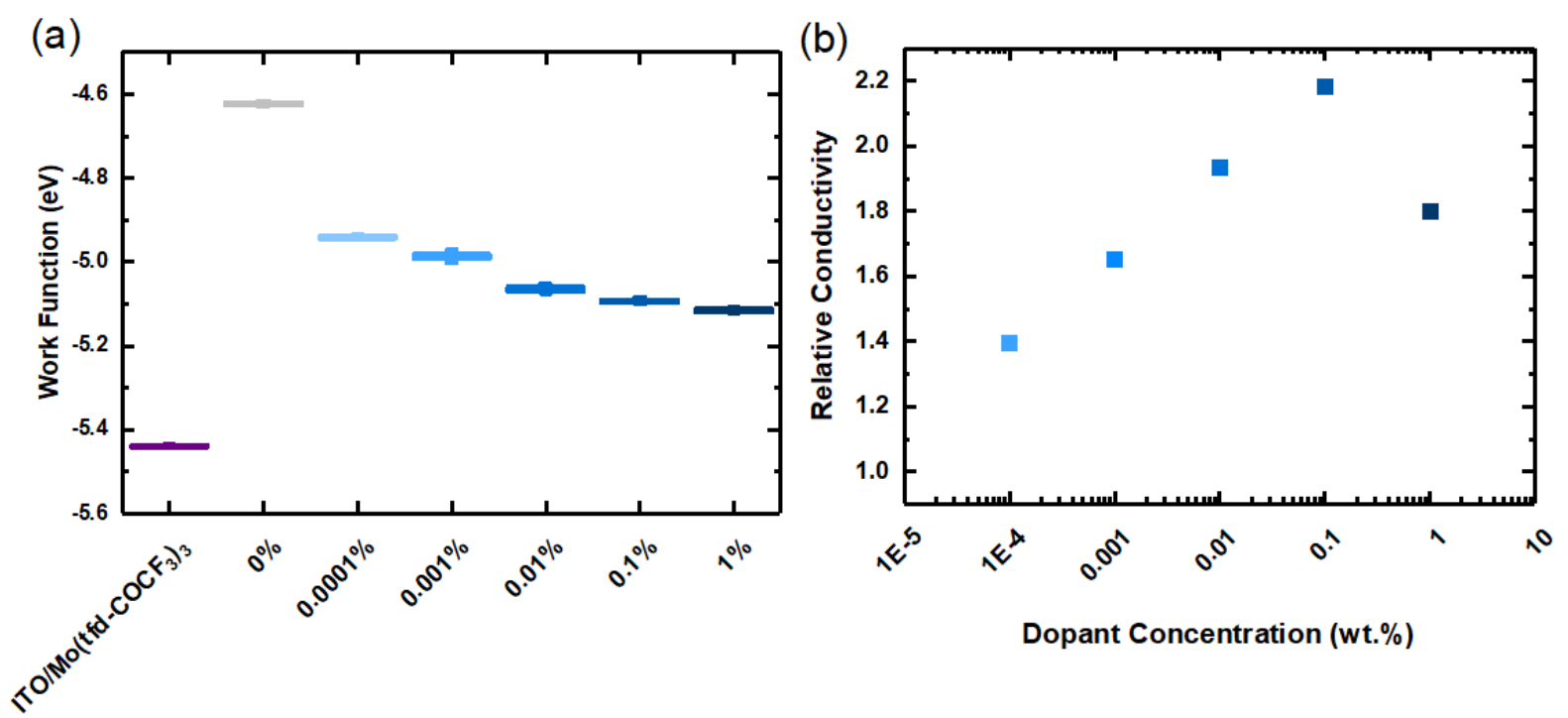

Figure 2: Kelvin Probe and Microwave Conductivity Measurements. (a) Work functions of the neat $\mathrm{Mo}\left(\mathrm{tfd}-\mathrm{COCF}_{3}\right)_{3}$ dopant, neat perovskite, and perovskite films treated with various concentrations of $\mathrm{Mo}\left(\mathrm{tfd}-\mathrm{COCF}_{3}\right)_{3}$ dopant. (b) Dark conductivities of neat and dopant-treated perovskite films as determined via microwave conductivity.

Next, we carry out Kelvin probe (KP) measurements (under $\mathrm{N}_{2}$ ) on both neat and dopant-treated perovskite films (Figure 3). The KP measurements in Fig. 3a show that treating the perovskite film with increasing concentrations of $\mathrm{Mo}\left(\mathrm{tfd}-\mathrm{COCF}_{3}\right)_{3}$ results in a significant increase in the absolute magnitude of the perovskite work function. The lowest dopant concentration of 0.0001 wt. $\%$ produces a shift of $320 \mathrm{meV}$, while $1.0 \mathrm{wt} . \%$ of $\mathrm{Mo}\left(\mathrm{tfd}-\mathrm{COCF}_{3}\right)_{3}$ results in a change of 500 meV. We show the corresponding work function values in Table S1. This shift is consistent with an increasing negative charge on the perovskite surface when it is treated with higher dopant concentrations, suggesting that there is a direct interaction between the dopant molecules and the perovskite. If this change in work function occurs because of electron transfer from the perovskite 
to the dopant complex, we expect both a shift in the Fermi level of the perovskite, as well as the formation of a surface dipole, which would both contribute to the observed shift in the work function. To investigate if a Fermi level shift, and thus p-doping, is indeed occurring, we probe the conductivity of the films with and without treatment. The relative conductivities (conductivities have been normalised to that of the control sample for ease of visualisation) of the neat and dopanttreated perovskite films were determined using dark microwave conductivity measurements, the results of which are shown in Fig. 2b. Here, we observe that, up to a critical dopant concentration, the change in the work function correlates to an increase in the dark conductivity of the film. At the lowest dopant concentration, the dark conductivity is 1.4 times that of the control film. We obtain the maximum conductivity at $0.1 \mathrm{wt} . \%$ where it is approximately twice that of the control film, after which the conductivity begins to decrease. This general increase in the dark conductivity is indicative of an increase in the density of mobile charge carriers within the films. The decrease in conductivity which occurs at the highest concentration could be due to two factors: increased cluster formation of the dopant on the surface, which may result in increased recombination, with clusters of unreacted dopant acting as trapping sites, or through making the perovskite material too strongly p-type, which has been shown to result in decreased carrier diffusion lengths, through reducing carrier lifetime. ${ }^{52}$ Based on both the size of the dopant molecule, as well as the relatively modest change in the dark conductivity, we can presume that the dopant molecules primarily remain on the surface of the perovskite film, and hence, produce a surface doping effect whereby only the perovskite surface effectively becomes more p-type. 

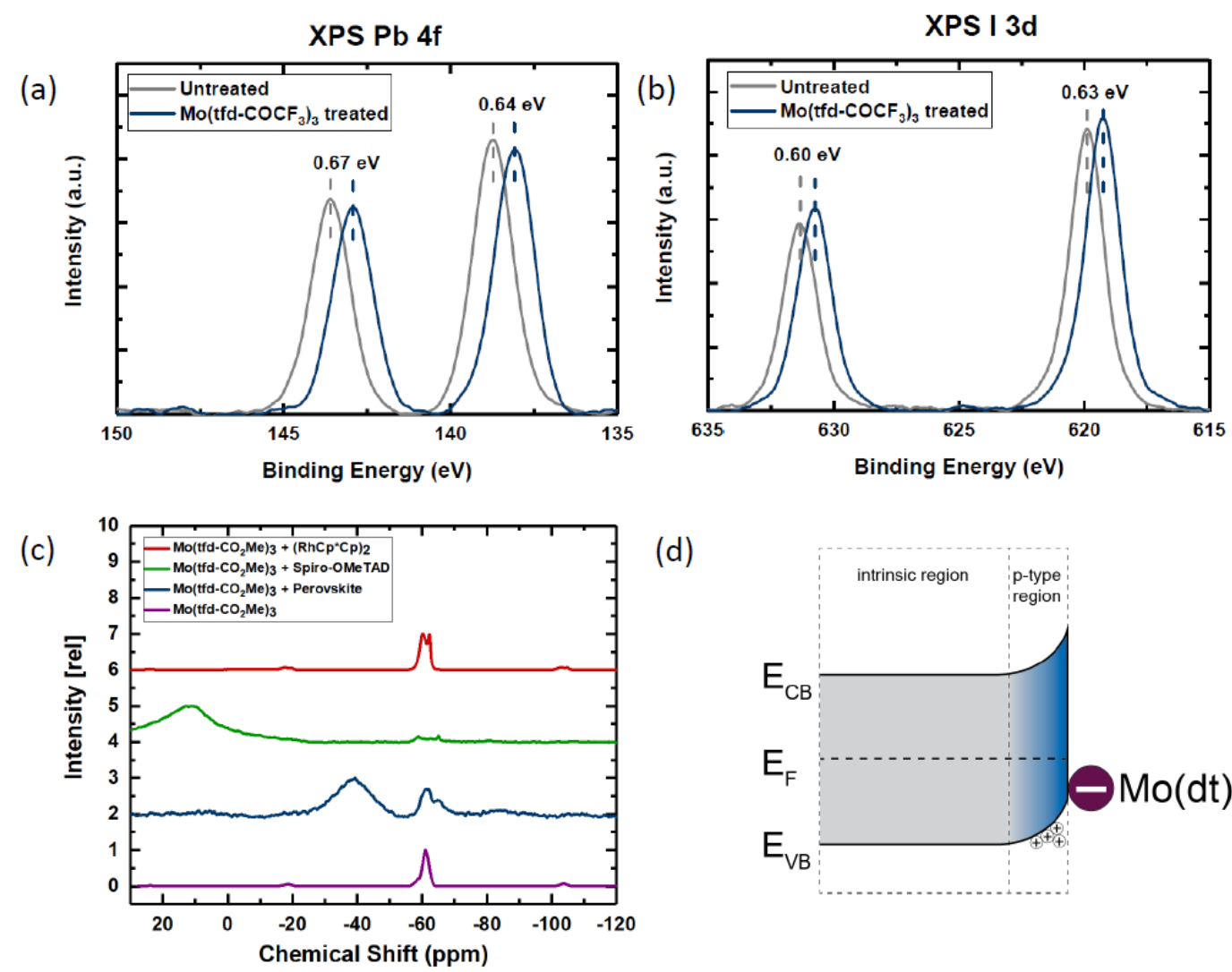

(d)

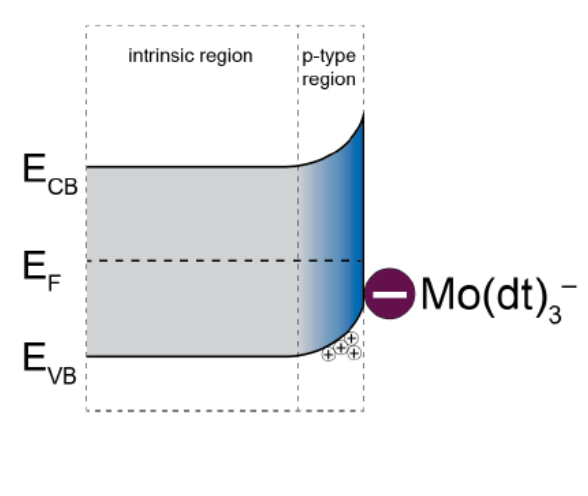

Figure 3. XPS spectra of the (a) $\mathrm{Pb} 4 \mathrm{f}$ and (b) I $3 \mathrm{~d}$ regions of neat and $\mathrm{Mo}\left(\mathrm{tfd}-\mathrm{COCF}_{3}\right)_{3}$-treated $\mathrm{FA}_{0.85} \mathrm{MA}_{0.15} \mathrm{~Pb}\left(\mathrm{I}_{0.85} \mathrm{Br}_{0.15}\right)_{3}$ perovskite films. (c) Solid-state ${ }^{19} \mathrm{~F}$ MAS NMR spectra of the neat $\mathrm{Mo}\left(\mathrm{tfd}-\mathrm{CO}_{2} \mathrm{Me}\right)_{3}$ dopant (deep purple trace), dopant treated $\mathrm{FA}_{0.85} \mathrm{MA}_{0.15} \mathrm{~Pb}\left(\mathrm{I}_{0.85} \mathrm{Br}_{0.15}\right)_{3}$ perovskite crystals (blue trace), $\mathrm{Mo}\left(\mathrm{tfd}-\mathrm{CO}_{2} \mathrm{Me}\right)_{3}$-doped spiro-OMeTAD in a 1:100 molar ratio (green trace), and $\mathrm{Mo}\left(\mathrm{tfd}-\mathrm{CO}_{2} \mathrm{Me}\right)_{3}$ reacted with a strong reductant, $\left(\mathrm{RhCp}{ }^{*} \mathrm{Cp}\right)_{2}$ in a 4:1 molar ratio (red trace). Here, $\mathrm{Mo}\left(\mathrm{tfd}-\mathrm{CO}_{2} \mathrm{Me}\right)_{3}$ was used for clarity as it has only one, clear ${ }^{19} \mathrm{~F}$ signal. (d) Illustration of proposed band bending at the surface of the perovskite crystal due to the chargetransfer reaction with $\mathrm{Mo}\left(\mathrm{tfd}-\mathrm{CO}_{2} \mathrm{Me}\right)_{3}$. 
To further investigate the chemistry at the $\mathrm{Mo}\left(\mathrm{tfd}-\mathrm{COCF}_{3}\right)_{3} /$ perovskite interface, we perform $\mathrm{X}$ ray photoelectron spectroscopy (XPS) studies on neat and dopant-treated perovskite films. A change in the electronic doping level, and thus in Fermi level position, should lead to a shift of the core level positions, in this case (p-type) toward lower binding energies. We show the $\mathrm{Pb} 4 \mathrm{f}$ and $\mathrm{I}$ 3d spectra in Figure 3. Both the $\mathrm{Pb}$ and I core level spectra shift by $0.6 \mathrm{eV}$ and $0.7 \mathrm{eV}$ toward lower binding energy for the dopant-treated perovskite as compared to the control sample, indicative of a shift in the Fermi level of the perovskite material, and consistent with p-doping of the perovskite surface.

To gain deeper insight into the doping effect, we perform ultraviolet photoelectron spectroscopy (UPS) and vacuum Kelvin probe (Vac-KP) measurements on undoped and p-doped perovskite thin films. The UPS measurements are performed with two standard radiation lines He I (21.22 eV) and He II $(40.8 \mathrm{eV})$. In UPS He I, the photoemission signal is measured with both a linear and a logarithmic detector, where the latter emphasizes the low density of state (DOS) part of the valence band spectrum, enabling a more accurate determination of the valence band maximum (VBM) in 3D perovskites. ${ }^{53}$ UPS He II on the other hand, probes deeper into the valence band, which helps to confirm orbitals of molecular dopants. The UPS spectra, as well as the work function measured by Vac-KP, are shown in Figure S4. From Fig. S4a, the WF of the perovskite, determined by linear extrapolation of the photoemission cut-off, increases from $4.67 \mathrm{eV}$ to $5.13 \mathrm{eV}$ when the surface is treated with $0.1 \mathrm{wt} . \%$ of $\mathrm{Mo}\left(\mathrm{tfd}-\mathrm{COCF}_{3}\right)_{3}$. This value is in good agreement with the WF obtained from vacuum KP measurements, suggesting that any UV damage to the perovskite sample is negligible. Figures S4b and S4c show that treating the perovskite surface induces a shift of the UPS spectra to lower binding energies, indicative of a corresponding shift of the Fermi level 
within the gap toward the VBM of the perovskite film. The shift in VBM as determined from Fig. $\mathrm{S} 3 \mathrm{c}$ is approximately $0.67 \mathrm{eV}$. We note that the magnitude of the shift in the VBM suggests that the shift in the WF measured by KP is almost entirely due to a shift in the Fermi level of the perovskite with minimal surface dipole contributions, further corroborating the assertion that treating the perovskite surface with $\mathrm{Mo}\left(\mathrm{tfd}-\mathrm{COCF}_{3}\right)_{3}$ results in a p-doping of the surface. The small contribution of the surface dipole could be due to random orientations of the individual dipoles causing a net effect which is quite small, or the presence of the polar $\mathrm{Mo}\left(\mathrm{tfd}-\mathrm{COCF}_{3}\right)_{3}{ }^{-}$monoanion on the perovskite surface being oriented in a manner that cancels out the dipole. Figure S3d shows the characteristic signal of the $\mathrm{Mo}\left(\mathrm{tfd}-\mathrm{COCF}_{3}\right)_{3}$ dopant, verifying the presence of the dopant on the perovskite surface.

Having investigated the effect of the dopant on the perovskite, we now probe changes in the dopant itself by carrying out ${ }^{19} \mathrm{~F}$ magic angle spinning (MAS) solid-state NMR spectroscopy on perovskite microcrystals treated with $\mathrm{Mo}\left(\mathrm{tfd}-\mathrm{CO}_{2} \mathrm{Me}\right)_{3}$ (an analogous Mo-dopant, where three of the trifluoromethyl groups are substituted with methoxy groups shown in Fig. 1). While this molecule is slightly less oxidizing, making it a weaker dopant, we have used this dopant complex as it exhibits a single, clear ${ }^{19} \mathrm{~F}$ signal, allowing for a less complex NMR spectrum. These experiments were carried out on single crystals of $\mathrm{FA}_{0.85} \mathrm{MA}_{0.15} \mathrm{~Pb}\left(\mathrm{I}_{0.85} \mathrm{Br}_{0.15}\right)_{3}$ grown using the inverse solubility method. ${ }^{54-56}$ Microcrystals were grown and crushed into a fine powder to increase the surface area over which the dopant could interact with the perovskite material, and subsequently treated with a solution of $\mathrm{Mo}\left(\mathrm{tfd}-\mathrm{CO}_{2} \mathrm{Me}\right)_{3}$. 
In Fig. 4c we compare the ${ }^{19} \mathrm{~F}$ MAS NMR spectra of the dopant treated perovskite sample to those of neutral $\mathrm{Mo}\left(\mathrm{tfd}-\mathrm{CO}_{2} \mathrm{Me}\right)_{3}$, spiro-OMeTAD doped with $\mathrm{Mo}\left(\mathrm{tfd}-\mathrm{CO}_{2} \mathrm{Me}\right)_{3}$, and $\mathrm{Mo}\left(\mathrm{tfd}-\mathrm{CO}_{2} \mathrm{Me}\right)_{3}$ treated with a strong reductant, $(\mathrm{RhCp} * \mathrm{Cp})_{2}$. The last two samples serve as model solid-state spectra of materials which contain the paramagnetic $\mathrm{Mo}\left(\mathrm{tfd}-\mathrm{CO}_{2} \mathrm{Me}\right){ }_{3}{ }^{-}$monoanion, which forms as a result of the dopant being reduced via an electron-transfer reaction. We have previously shown that $\mathrm{Mo}\left(\mathrm{tfd}-\mathrm{CO}_{2} \mathrm{Me}\right)_{3}$ can be used to $\mathrm{p}$-dope spiro-OMeTAD, resulting in the formation of the $\mathrm{Mo}\left(\mathrm{tfd}-\mathrm{CO}_{2} \mathrm{Me}\right)_{3}{ }^{-}$monoanion, and the paramagnetic spiro-OMeTAD ${ }^{+}$cation. ${ }^{41}$ Similarly, the Modopant reacts with $\left(\mathrm{RhCp}^{*} \mathrm{Cp}\right)_{2}$, a much stronger reductant than spiro-OMeTAD, resulting in the formation of the $\mathrm{Mo}\left(\mathrm{tfd}-\mathrm{CO}_{2} \mathrm{Me}\right)_{3}{ }^{-}$monoanion, and the diamagnetic $\mathrm{RhCp}^{*} \mathrm{Cp}^{+}$cation.

The $\mathrm{Mo}\left(\mathrm{tfd}-\mathrm{CO}_{2} \mathrm{Me}\right)_{3}+$ spiro-OMeTAD sample exhibits a dominant, broad peak at $8 \pm 1 \mathrm{ppm}$ due to the presence of the $\mathrm{Mo}\left(\mathrm{tfd}-\mathrm{CO}_{2} \mathrm{Me}\right)_{3}{ }^{-}$monoanion. Additionally, we observe trace signals at -58 ppm (which likely correspond to unreacted $\left.\mathrm{Mo}\left(\mathrm{tfd}-\mathrm{CO}_{2} \mathrm{Me}\right)_{3}\right)$, and at $-65 \mathrm{ppm}$. We hypothesise that the signal at $-65 \mathrm{ppm}$ is also due to the presence of the monoanion, but in a different magnetic environment, for example, in close proximity to the unreacted dopant, which is diamagnetic, rather than paramagnetic spiro-OMeTAD ${ }^{+}$. To test this hypothesis, we analyse the $\mathrm{Mo}\left(\mathrm{tfd}-\mathrm{CO}_{2} \mathrm{Me}\right)_{3}+$ $(\mathrm{RhCp} * \mathrm{Cp})_{2}$ sample, which is expected to contain a 1:1 mixture of neutral and anionic Mo(tfd$\left.\mathrm{CO}_{2} \mathrm{Me}\right)_{3}$, as well as diamagnetic $\mathrm{RhCp} * \mathrm{Cp}^{+}$ions. In contrast to the $\mathrm{Mo}\left(\mathrm{tfd}-\mathrm{CO}_{2} \mathrm{Me}\right)_{3}+$ spiroOMeTAD spectrum, here we observe two overlapping, relatively narrow signals at similar chemical shifts to the unreacted dopant. It is evident therefore, that the chemical shift and lineshape of the ${ }^{19} \mathrm{~F}$ signal from the $\mathrm{Mo}\left(\mathrm{tfd}-\mathrm{CO}_{2} \mathrm{Me}\right)_{3}{ }^{-}$monoanion is strongly dependent on its magnetic environment, yielding distinctly different spectra when in contact with paramagnetic vs. diamagnetic species. Presumably, in the case of the spiro-OMeTAD sample, most of the dopant 
monoanions are adjacent to the paramagnetic spiro-OMeTAD ${ }^{+}$, while in the $\left(\mathrm{RhCp}^{*} \mathrm{Cp}\right)_{2}$ sample, they interact equally with $\mathrm{RhCp} * \mathrm{Cp}^{+}$ions and unreacted $\mathrm{Mo}\left(\mathrm{tfd}-\mathrm{CO}_{2} \mathrm{Me}\right)_{3}$, both of which are diamagnetic species.

The dopant treated perovskite exhibits a strong, broad feature at -39 ppm, along with sharper and weaker peaks at $-60 \mathrm{ppm}$ and $-65 \mathrm{ppm}$. Based on our model spectra, we can attribute the major peak at $-39 \mathrm{ppm}$ to $\mathrm{Mo}\left(\mathrm{tfd}-\mathrm{CO}_{2} \mathrm{Me}\right)_{3}{ }^{-}$monoanions near other paramagnetic species (specifically other $\mathrm{Mo}\left(\mathrm{tfd}-\mathrm{CO}_{2} \mathrm{Me}\right)_{3}{ }^{-}$ions on the perovskite surface), while we assign the peak at $-60 \mathrm{ppm}$ to unreacted dopant since we observe a similar peak in the ${ }^{19} \mathrm{~F}$ MAS NMR spectrum of pure Mo(tfd$\left.\mathrm{CO}_{2} \mathrm{Me}\right)_{3}$ (a comparable chemical shift of $-56.6 \mathrm{ppm}$ is seen for the neutral dopant in solution ). ${ }^{57}$ As is the case in the $\mathrm{Mo}\left(\mathrm{tfd}-\mathrm{CO}_{2} \mathrm{Me}\right)_{3}+$ spiro-OMeTAD sample, the minor feature at approximately $-65 \mathrm{ppm}$ is likely due to $\mathrm{Mo}\left(\mathrm{tfd}-\mathrm{CO}_{2} \mathrm{Me}\right)_{3}{ }^{-}$monoanions in a more diamagnetic environment, i.e., closer proximity of the monoanion to unreacted dopant, or better separation from other paramagnetic species.

The combination of the photoelectron spectroscopy (PES) and ss-NMR data provides us with a complete picture of the charge-transfer reaction occurring between the $\mathrm{Mo}\left(\mathrm{tfd}-\mathrm{COCF}_{3}\right)_{3}$ dopant and the perovskite material. The PES measurements show a shift of the Fermi level toward to VBM at the perovskite surface. This shift results from an electron transfer from the valence band of the perovskite to the dopants with a concomitant increase in the surface hole density, as confirmed by ss-NMR showing the formation of the $\mathrm{Mo}\left(\mathrm{tfd}-\mathrm{CO}_{2} \mathrm{Me}\right)_{3}{ }^{-}$anions. 

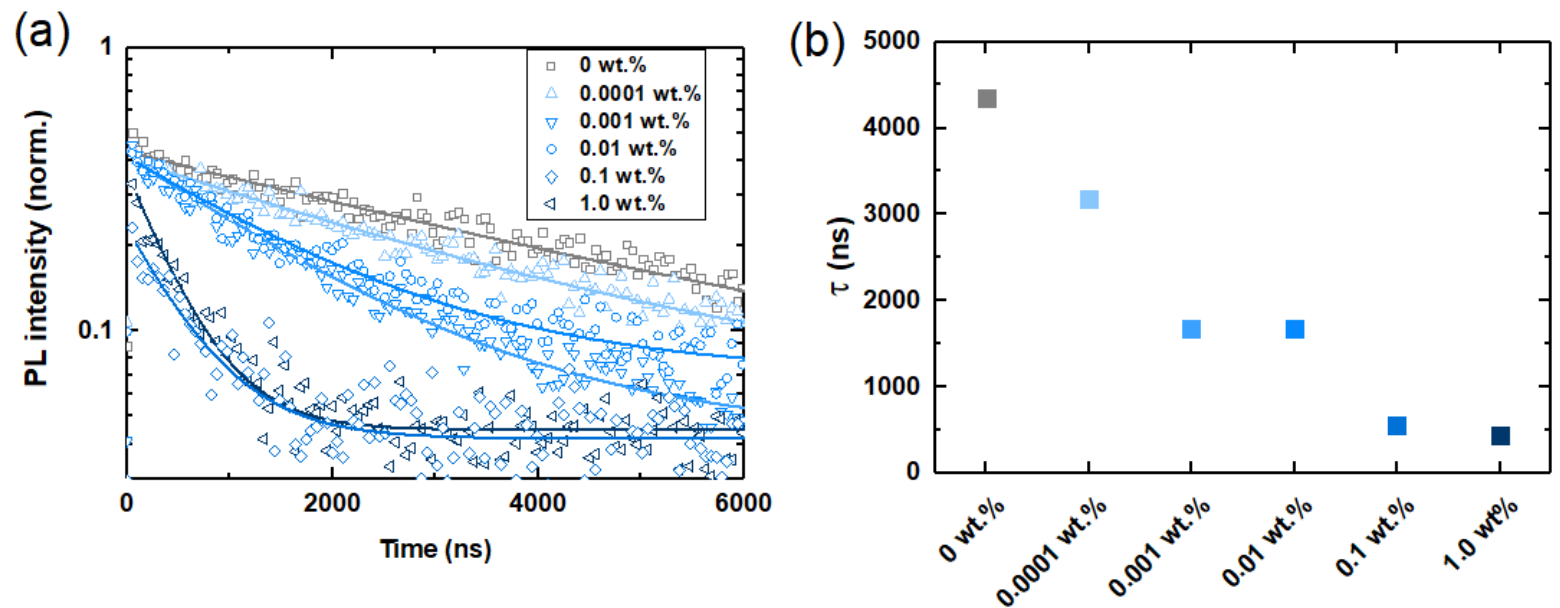

Figure 4. (a) Time-resolved photoluminescence of neat and $\mathrm{Mo}\left(\mathrm{tfd}-\mathrm{COCF}_{3}\right)_{3}$-treated perovskite films. The data are shown with open symbols and fits are depicted using solid lines of corresponding colour. Samples were excited with a $505 \mathrm{~nm}$ laser source at a fluence of 0.187 $\mathrm{nJ} / \mathrm{cm}^{2}$. (b) Lifetimes extracted from the fits shown in (a).

Having confirmed that the $\mathrm{Mo}\left(\mathrm{tfd}-\mathrm{COCF}_{3}\right)_{3}$ complex is, in fact, able to dope the perovskite material, we move on to probe the effects of this surface doping on the optoelectronic properties of the perovskite film. To investigate this, we carry out time-resolved photoluminescence (PL) measurements. We show a Mo(tfd- $\left.\mathrm{COCF}_{3}\right)_{3}$-treated sample measured at both high and low fluences in Figure S5. We note that when exciting at the lowest fluence $\left(0.187 \mathrm{~nJ} / \mathrm{cm}^{2}\right)$, we mainly probe trap-assisted, non-radiative recombination since the carrier population is sufficiently low for trap-assisted recombination to be the dominant recombination pathway. ${ }^{58}$ Accordingly, at low fluence, the PL decay is monomolecular, and as such can be fit to a monoexponential function in order to extract a lifetime, $\tau$. Figure 4 shows the PL decays of neat and dopant-treated perovskite films. We note that both the untreated and $\mathrm{Mo}\left(\mathrm{tfd}-\mathrm{COCF}_{3}\right)_{3}$-treated samples exhibit a sharp drop 
in the PL within the first 10 ns of the decay (see Figure S5). This sharp decay is present at both high and low fluences, indicating that it is likely due to carrier dilution via diffusion, rather than rapid recombination events. ${ }^{59}$ This initial drop was excluded in the fitting parameters. We observe a near continuous decrease in the PL lifetime of the Mo-treated films. This decrease scales with increasing dopant concentration, by an order of magnitude from $4350 \mathrm{~ns}$ in the untreated film to $440 \mathrm{~ns}$ in the film treated with $1.0 \mathrm{wt} . \%$ of $\mathrm{Mo}\left(\mathrm{tfd}-\mathrm{COCF}_{3}\right)_{3}$.

Before we rationalize our observations, we first summarize the general understanding of charge trapping and recombination in these metal halide perovskite materials. There is much evidence that the predominant trapped carriers are electrons, and generally under illumination, a steady-state hole density $\left(\mathrm{p}_{0}\right)$ exists, which balances the density of trapped electrons. If an additional increase in the hole density occurs, which can occur for instance when electrically biasing a device due to the combined effect ion ionic and electronic diffusion ${ }^{60}$ then depopulation of the trapped electrons speeds up, and hence the density of available trap sites increases. This increase in the density of available traps (i.e. vacant traps) is rationalized to be reason why the carrier lifetime and carrier diffusion length is much shorter is perovskite absorbers with p-type character. ${ }^{35,52}$

From the experimental results previously discussed, we can surmise that our treated perovskite films are p-doped at the surface, rather than through the entire bulk. Based on this, we expect the surface of the perovskite to become more hole-rich, thereby increasing the degree of recombination near this surface region. This would therefore be consistent with our observed reduction in PL lifetime. This result is consistent with a recent finding by Ramirez et al., who investigated the differing material properties when the perovskite film is deposited onto mesoporous scaffolds, and crystallised on either n-type or p-type substrates. ${ }^{52}$ It was observed that when the perovskite was crystallised within a porous scaffold atop a p-type $\mathrm{NiO}$ substrate, the electronic character of the 
perovskite was significantly more p-type. The resulting films exhibited significantly shorter PL lifetimes and electron diffusion lengths, indicating the requirement, here, for a very narrow p-type region to maintain desirable optoelectronic characteristics.

The band bending induced by the molecular dopant should increase the hole selectivity of the treated perovskite surface. To test this, we incorporate the perovskite layer into a series of devices without selective contacts and present the results in Figure S6. Through measuring the dark current-voltage $(J-V)$ characteristics and fitting them to the ideal diode equation, we can extract the reverse saturation current, $J_{0}$. For lower dopant concentrations, $J_{0}$ decreases with increasing doping concentration which indicates that surface charge recombination is suppressed by the surface treatment. The lowest $J_{0}$ is achieved with a dilution of $0.01 \mathrm{wt} . \%$ of the dopant (high magnification SEM images (Figure S7) confirm that at this concentration, the perovskite surface remains unchanged). We attribute this behaviour to the increase in the magnitude of the work function (Fig. 3a), and an effective p-doping of this interface. The p-type character of the interface is likely to make the interface more hole-selective, i.e., more favourable for hole extraction, whilst in principle repelling photogenerated electrons. Consequently, charges should be more effectively separated at the perovskite-gold interface and fewer electrons will be able to recombine at the $\mathrm{Au} /$ perovskite interface. However, at higher doping concentrations, namely $0.1 \mathrm{wt} . \%$ and 1.0 wt.\%, the trend is reversed and $J_{0}$ increases by orders of magnitude with higher doping concentrations, indicative of a significant increase in the recombination rate at the interface. This is likely due to the onset of much faster recombination in the p-type region, as the perovskite becomes increasingly p-doped. It is, therefore, likely that an optimal doping concentration exists, where a small amount of dopant improves the hole selectivity of the contact and reduces the 
electron density at the perovskite/Au interface, but too much doping leads to rapid recombination of minority carriers (electrons) within this doped region.

Having demonstrated that the treatment-induced changes in the hole density at the perovskite surface results in increased charge selectivity of the interface, we proceed to examine the influence of the dopant in a full device with charge-selective layers. To probe this, we use the n-i-p device configuration and employ a matrix of single-walled carbon nanotubes (SWCNTs) and spiroOMeTAD as the hole-transport layer. ${ }^{61}$ We present the device performance parameter statistics in Figure S7. From the batch statistics we see that while the short-circuit current density $\left(J_{S C}\right)$ remains relatively constant up to $0.01 \mathrm{wt} . \%$, both the $V_{O C}$ and the $F F$ increase, resulting in an improvement in the PCE of the devices. At higher dopant concentrations there is a notable decrease in all three parameters. This is could be due to a confluence of factors. It is likely that at high doping concentrations, the perovskite film becomes too strongly p-type, and the faster recombination in the top surface region of the perovskite film begins to negatively affect the open-circuit voltage and charge extraction. ${ }^{52}$ Furthermore, at $0.1 \mathrm{wt} . \%$ the dopant is very near its solubility limit in chlorobenzene. Hence, when it is deposited onto the surface of the perovskite, in addition to forming agglomerates of unreacted dopant, as we see in the SEM images (Fig. S3), it likely forms a thicker dopant film, a significant portion of which would consist of unreacted dopant. This will act to inhibit charge extraction, thus causing the observed decrease in FF of the solar cells. We show the $J V$ characteristics of the best performing control and Mo-treated devices in Figure 5 and give their performance parameters in Table 1. 
(a)

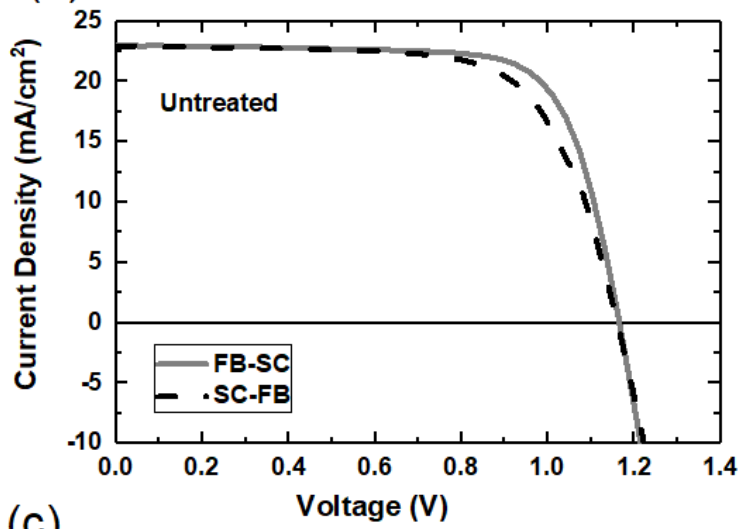

(c)

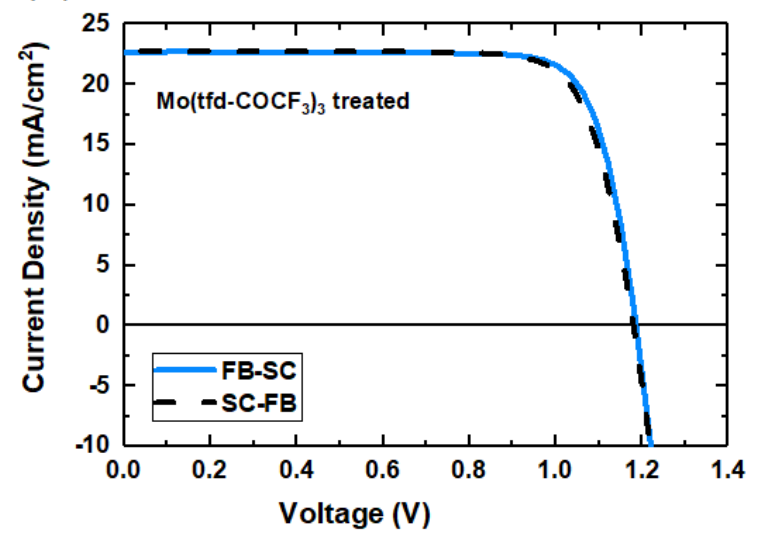

(b)

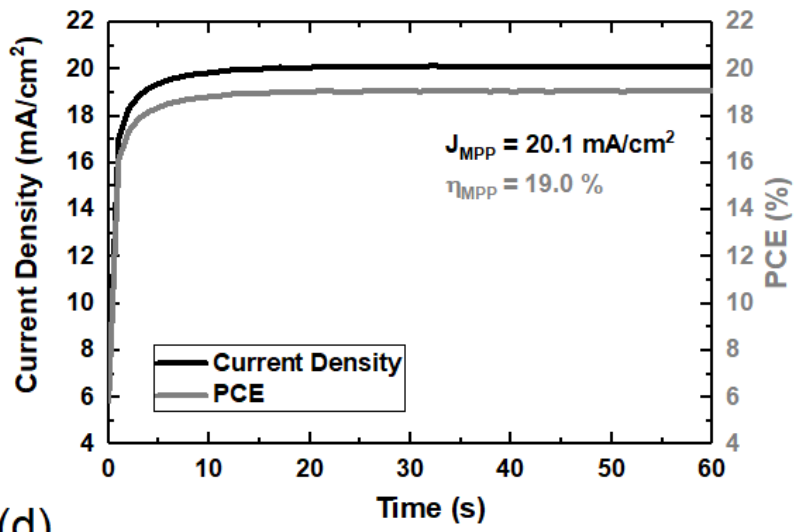

(d)

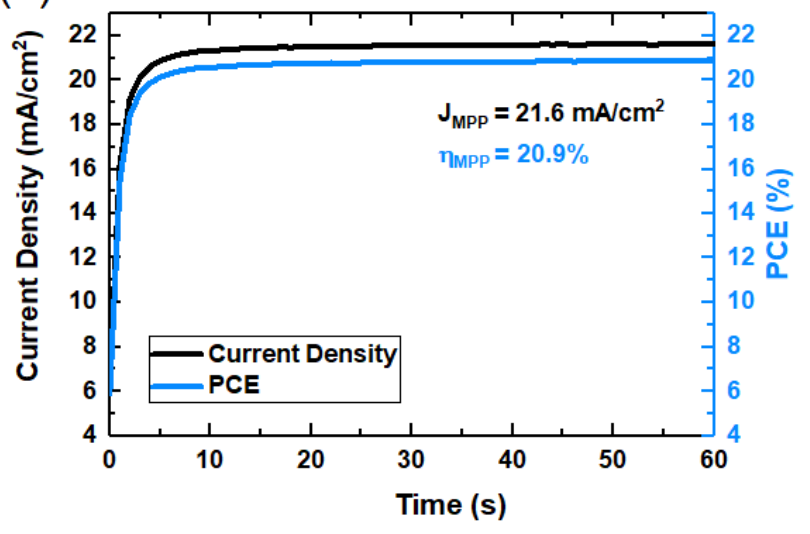

Figure 7. (a) and (c) Current density-voltage characteristics under 1 sun simulated AM1.5G solar illumination of the best performing treated and untreated solar cells respectively. (b) and (d) Steady-state current density and efficiency of devices shown in (a) and (c). Measurements were taken by holding the respective devices at their maximum power point (MPP) voltages for $60 \mathrm{~s}$.

\begin{tabular}{lccccc}
\hline & $\boldsymbol{J}_{S C}\left(\mathbf{m A} / \mathbf{c m}^{2}\right)$ & Voc $(\mathbf{V})$ & FF & PCE (\%) & PCEMPP (\%) \\
\hline Untreated & 22.9 & 1.16 & 0.74 & 19.7 & 19.0 \\
(champion) & & & & & \\
\hline
\end{tabular}




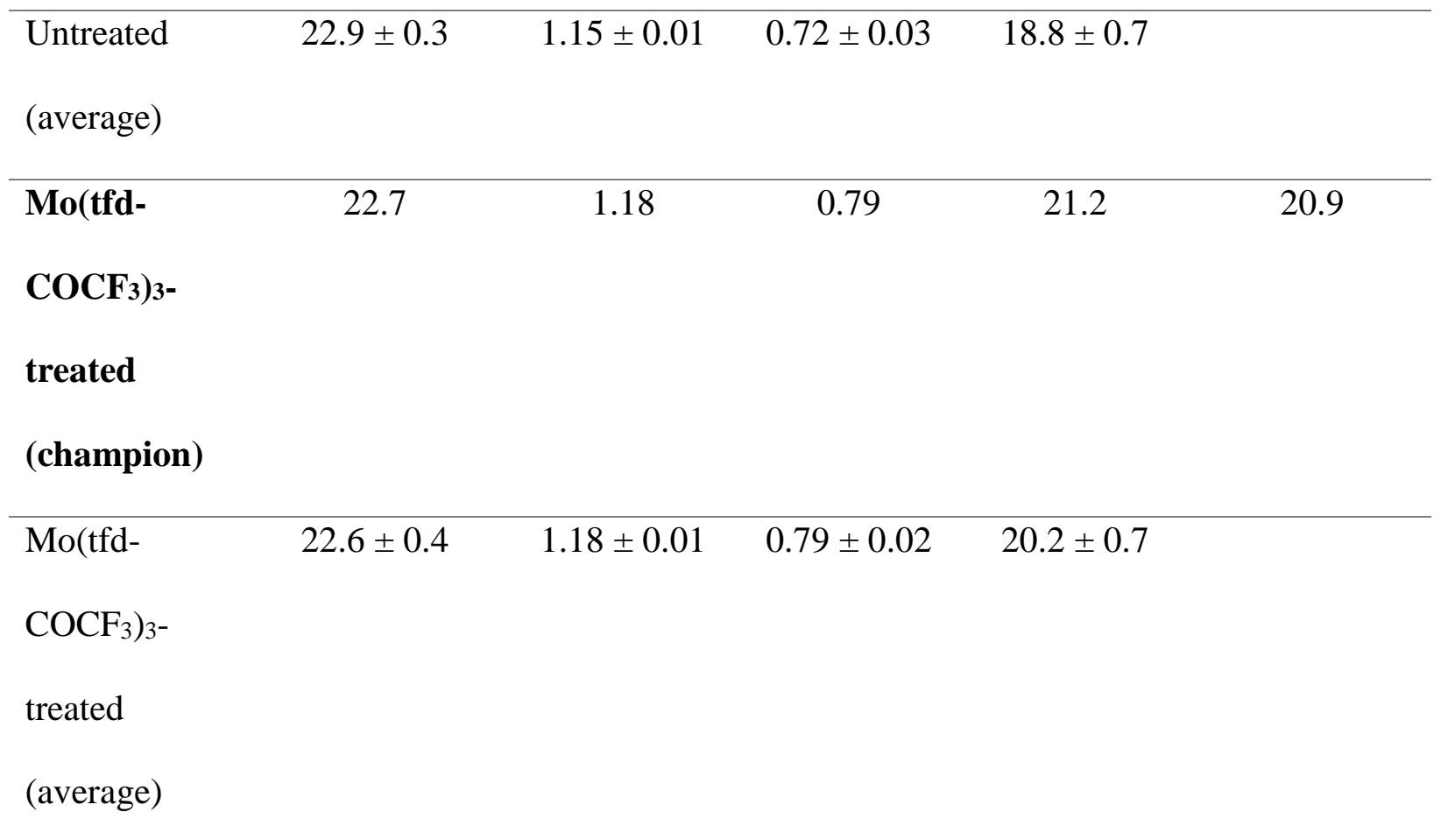

Table 1. Champion and average device performance parameters for solar cells fabricated from untreated and $\mathrm{Mo}\left(\mathrm{tfd}-\mathrm{COCF}_{3}\right)_{3}$-treated perovskite films measured under 1 sun simulated AM1.5G solar illumination. The values given in this table represent scans from reverse bias to short-circuit conditions.

From the data shown in Fig. 7 and Table 1, we see that treating the perovskite surface with Mo(tfd$\left.\mathrm{COCF}_{3}\right)_{3}$ causes a significant increase in both the $V_{O C}$ and $F F$ of the solar cells. This is indicative of a reduction in recombination, and enhanced charge extraction at the p-type interface. Along with the enhancements in $V_{O C}$ and $F F$, the $\mathrm{Mo}\left(\mathrm{tfd}-\mathrm{COCF}_{3}\right)_{3}$ devices also exhibit suppressed hysteresis and higher steady-state efficiencies, a result often observed through improving the interfaces in perovskite-based solar cells. ${ }^{62}$ Common examples of this involve surface passivation of the perovskite or modification of the charge collection layers in the device. ${ }^{17,24,63}$ We have 
previously shown that $\mathrm{Mo}(\mathrm{dt})_{3}$ complexes can be used as dopants for spiro-OMeTAD, enabling the fabrication of efficient perovskite solar cells. ${ }^{41}$ Here, to exclude the possibility that the observed improvements in device performance are due to the doping of the HTM by Mo(tfd$\left.\mathrm{COCF}_{3}\right)_{3}$, we also prepare devices where the spiro-OMeTAD was oxidised in solution prior to deposition and show the results in Figure S8. We note that even in this case there is a similar improvement in the steady-state device performance when the perovskite surface is treated with $\mathrm{Mo}\left(\mathrm{tfd}-\mathrm{COCF}_{3}\right)_{3}$, thus ruling out an increase in HTM conductivity as being the underlying cause for the enhancement in device efficiency.

We have previously shown that $t \mathrm{BP}$ directly interacts with the perovskite layer and causes a 'pdoping' of the perovskite/HTM interface through the formation of a charge accumulation layer. ${ }^{42}$ This causes upward band bending and allows for more efficient hole extraction and thus, reduced interfacial recombination and improved steady state efficiencies. We propose a similar effect with the introduction of the $\mathrm{Mo}\left(\mathrm{tfd}-\mathrm{COCF}_{3}\right)_{3}$ layer, where directly p-doping the perovskite surface results in upward band bending and thus, in enhanced charge extraction at the p-type interface. If both the $\mathrm{Mo}\left(\mathrm{tfd}-\mathrm{COCF}_{3}\right)_{3}$ and $t \mathrm{BP}$ serve the same function, it stands to reason that by surface doping the perovskite with $\mathrm{Mo}\left(\mathrm{tfd}-\mathrm{COCF}_{3}\right)_{3}$ we could obviate the need for $t \mathrm{BP}$ in spiro-OMeTAD based devices. It is important to note here, that $t \mathrm{BP}$ may have an additional role in adjusting the $\mathrm{pH}$ of the spiro-OMeTAD solution such that the conventional Li-TFSI dopant remains solubilised. Here, since we rely on SWCNTs for rapid charge extraction, we forgo the need for a dopant in spiro-OMeTAD and can thus isolate the role of $t \mathrm{BP}$ as an interfacial modifier. 
(a)

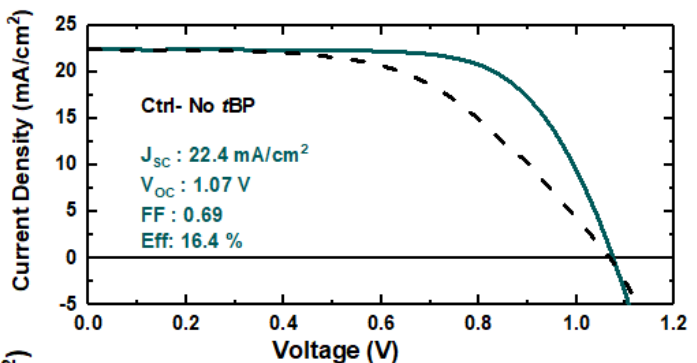

(c)

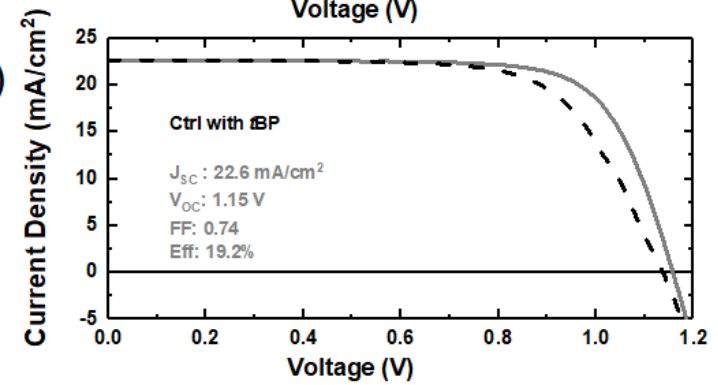

(e)

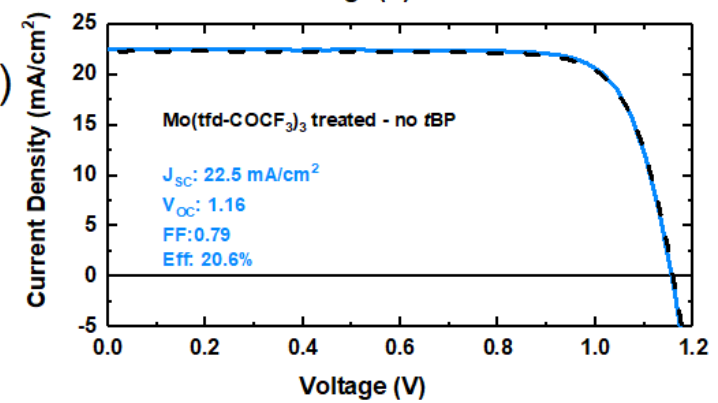

(b)

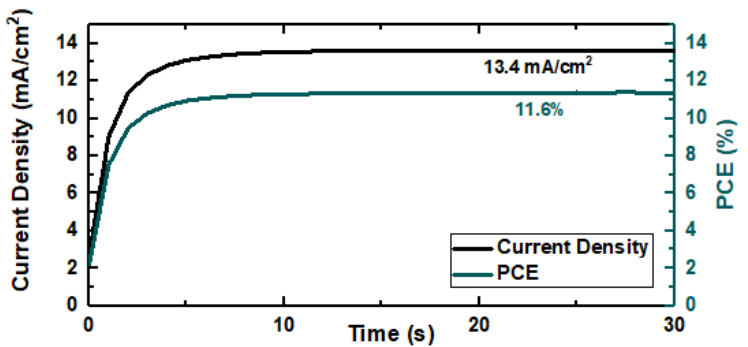

(d)

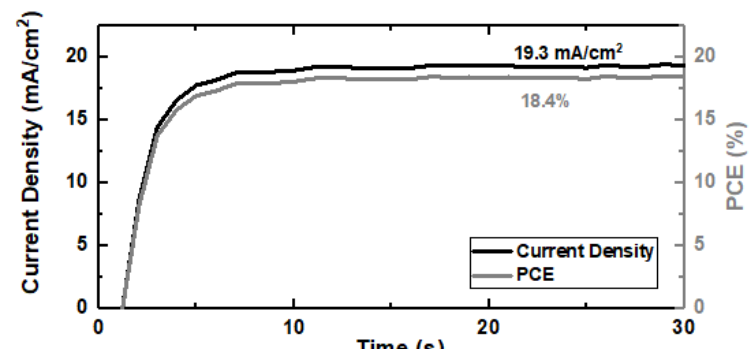

(f)

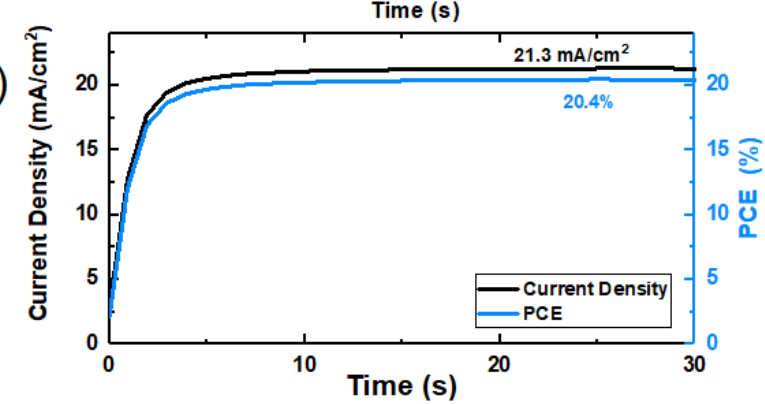

Figure 8. Current density-voltage characteristics and steady-state efficiencies of perovskite solar cells fabricated with (a) and (b) SWNTs and spiro-OMeTAD, (c) and (d) SWNTs, spiroOMeTAD and $t \mathrm{BP}$, (e) and (f) Mo(tfd- $\left.\mathrm{COCF}_{3}\right)_{3}, \mathrm{SWNT}$ and spiro-OMeTAD (no $t \mathrm{BP}$ ).

To test this hypothesis, we fabricate devices with and without $t \mathrm{BP}$. We show the $J V$ characteristics and steady-state efficiencies in Figure 8. The comparison of devices with and without $t \mathrm{BP}$ confirms previous observations that the presence of $t \mathrm{BP}$ significantly improves the device performance by enhancing $V_{O C}$ and $F F$, and, most notably, the steady-state efficiency. Remarkably, however, $t$ BP-free devices, made with perovskite films treated with Mo(tfd$\left.\mathrm{COCF}_{3}\right)_{3}$, outperform the control device which was fabricated with $t \mathrm{BP}$, achieving a steady-state 
efficiency of $20.4 \%$. This strongly corroborates our hypothesis that deliberate, controlled p-doping with $\mathrm{Mo}\left(\mathrm{tfd}-\mathrm{COCF}_{3}\right)_{3}$ has a similar effect as the incidental effect of $t \mathrm{BP}$ on device performance in perovskite solar cells. In addition, recent studies have discussed the detrimental effects of $t \mathrm{BP}$ on the long-term stability of perovskite solar cells. ${ }^{64-66} \mathrm{We}$ propose surface doping of the perovskite material with molecules such as $\mathrm{Mo}\left(\mathrm{tfd}-\mathrm{COCF}_{3}\right)_{3}$ as a means to improve charge extraction, and hence device performance of perovskite solar cells, without the potentially harmful long-term effects of $t \mathrm{BP}$. Indeed, preliminary stability tests (Figure S9) show improved performance of $\mathrm{Mo}\left(\mathrm{tfd}-\mathrm{COCF}_{3}\right)_{3}$ treated devices after $>800 \mathrm{~h}$ thermal stressing at $85{ }^{\circ} \mathrm{C}$ in the dark, with $t \mathrm{BP}$-free devices outperforming devices fabricated with $t \mathrm{BP}$. These results indicated that interface doping is a promising route to further improving both the efficiency and stability of perovskite photovoltaics.

\section{Conclusion:}

In summary, we have investigated the interaction between the mixed-cation, mixed-halide perovskite, $\mathrm{FA}_{0.85} \mathrm{MA}_{0.15} \mathrm{~Pb}\left(\mathrm{I}_{0.85} \mathrm{Br}_{0.15}\right)_{3}$, and a strongly electron-withdrawing dopant, Mo(tfd$\left.\mathrm{COCF}_{3}\right)_{3}$. We find that treating the surface of the perovskite film with a dilute solution of this dopant results in a shift in the work function, an increase in the dark conductivity, and a decrease in the photoluminescence lifetime of the perovskite film, indicating an increase in the hole density at the perovskite interface. Through XPS and UPS measurements we confirm the shift of the Fermi level towards the valence band near the perovskite surface, while solid-state NMR spectroscopy shows the formation of the $\mathrm{Mo}(\mathrm{dt})_{3}$ monoanion, indicating an electron-transfer reaction between the perovskite and the $\mathrm{Mo}(\mathrm{dt})_{3}$ complexes. By incorporating the $\mathrm{Mo}\left(\mathrm{tfd}-\mathrm{COCF}_{3}\right)_{3}$-treated films into solar cells we obtain improved charge extraction at the p-type interface, resulting in devices 
with steady-state efficiencies approaching $21 \%$. Additionally, we find that by using this dopant to $\mathrm{p}$-dope the perovskite surface, we obviate the need for $t \mathrm{BP}$, resulting in improved thermal stability of the perovskite solar cell. Here, we have established a method of extrinsically doping the perovskite material and have shown the application of interfacial doping to perovskite devices, providing a potential avenue for highly efficient perovskite photovoltaics with improved long-term stability. The establishment of charge-transfer doping in perovskite materials may prove to be a key development in the fabrication of stable perovskite homojunctions, increasing the competitiveness of perovskite-based optoelectronics.

\section{Conflicts of Interest:}

The authors declare no conflicting interests.

\section{Acknowledgements:}

This work was partly funded by the US Air Force Office of Scientific Research (Awards FA955015-1-0115 and FA9550-18-1-0499), Office of Naval Research (ONR) Young Investigator Program (Award \#N00014-17-1-2005), and by ExxonMobil through its membership in the Princeton Efilliates Partnership of the Andlinger Center for Energy and the Environment. N.K.N acknowledges funding via a fellowship from the Princeton Center for Complex Materials (PCCM). B.W. acknowledges funding from the European Commission via a Marie Skłodowska-Curie individual fellowship (REA Grant Number 706552-APPEL). Support of F. Z. and A. K. by the National Science Foundation (DMR-1807797) is gratefully acknowledged. S.N.H. was supported by the Director's Fellowship program of the National Renewable Energy Laboratory under 
Contract No. DE-AC36-08GO28308. This work was authored in part by Alliance for Sustainable Energy, LLC, the manager and operator of the National Renewable Energy Laboratory for the U.S. Department of Energy (DOE) under Contract No. DE-AC36-08GO28308.

\section{References:}

1 Z.-K. Tan, R. S. Moghaddam, M. L. Lai, P. Docampo, R. Higler, F. Deschler, M. Price, A. Sadhanala, L. M. Pazos, D. Credgington, F. Hanusch, T. Bein, H. J. Snaith and R. H. Friend, Nat Nano, 2014, 9, 687-692.

2 Z. Xiao, R. A. Kerner, L. Zhao, N. L. Tran, K. M. Lee, T.-W. Koh, G. D. Scholes and B. P. Rand, Nat. Photonics, 2017, 11, 108.

3 F. Deschler, M. Price, S. Pathak, L. E. Klintberg, D.-D. Jarausch, R. Higler, S. Hüttner, T. Leijtens, S. D. Stranks, H. J. Snaith, M. Atatüre, R. T. Phillips and R. H. Friend, J. Phys. Chem. Lett., 2014, 5, 1421-1426.

4 Y. Jia, R. A. Kerner, A. J. Grede, B. P. Rand and N. C. Giebink, Nat. Photonics, 2017, 11, 784-788.

5 H.-S. Kim, C.-R. Lee, J.-H. Im, K.-B. Lee, T. Moehl, A. Marchioro, S.-J. Moon, R. Humphry-Baker, J.-H. Yum, J. E. Moser, M. Grätzel and N.-G. Park, Sci. Rep., 2012, 2, 591.

6 M. M. Lee, J. Teuscher, T. Miyasaka, T. N. Murakami and H. J. Snaith, Science, 2012, 338, 643-647. 
7 V. Sivaram, S. D. Stranks and H. J. Snaith, Sci. Am., 2015, 313, 54-59.

8 A. Kojima, K. Teshima, Y. Shirai and T. Miyasaka, J. Am. Chem. Soc., 2009, 131, 60506051.

$9 \quad$ N. R. E. L. (NREL), Best Research-Cell Efficiencies, https://www.nrel.gov/pv/assets/pdfs/pv-efficiencies-07-17-2018.pdf.

10 S. D. Stranks, G. E. Eperon, G. Grancini, C. Menelaou, M. J. P. Alcocer, T. Leijtens, L. M. Herz, A. Petrozza and H. J. Snaith, Science, 2013, 342, 341-344.

11 V. D’Innocenzo, G. Grancini, M. J. P. Alcocer, A. R. S. Kandada, S. D. Stranks, M. M. Lee, G. Lanzani, H. J. Snaith and A. Petrozza, Nat. Commun., 2014, 5, 3586.

12 S. D. Stranks and H. J. Snaith, Nat. Nanotechnol., 2015, 10, 391.

13 G. E. Eperon, V. M. Burlakov, P. Docampo, A. Goriely and H. J. Snaith, Adv. Funct. Mater., 2014, 24, 151-157.

14 D. P. McMeekin, Z. Wang, W. Rehman, F. Pulvirenti, J. B. Patel, N. K. Noel, M. B. Johnston, S. R. Marder, L. M. Herz and H. J. Snaith, Adv. Mater., 2017, 29, 1607039.

15 N. K. Noel, S. N. Habisreutinger, B. Wenger, M. T. Klug, M. T. Horantner, M. B. Johnston, R. J. Nicholas, D. T. Moore and H. J. Snaith, Energy Environ. Sci., 2017, 10, $145-152$.

16 N. K. Noel, M. Congiu, A. J. Ramadan, S. Fearn, D. P. McMeekin, J. B. Patel, M. B. Johnston, B. Wenger and H. J. Snaith, Joule, 2018, 1, 328-343.

17 N. K. Noel, A. Abate, S. D. Stranks, E. S. Parrott, V. M. Burlakov, A. Goriely and H. J. Snaith, ACS Nano, 2014, 8, 9815-9821. 
18 W. Zhang, M. Saliba, D. T. Moore, S. K. Pathak, M. T. Hörantner, T. Stergiopoulos, S. D. Stranks, G. E. Eperon, J. A. Alexander-Webber, A. Abate, A. Sadhanala, S. Yao, Y. Chen, R. H. Friend, L. A. Estroff, U. Wiesner and H. J. Snaith, Nat. Commun., 2015, 6, 6142.

19 M. Saliba, T. Matsui, J.-Y. Seo, K. Domanski, J.-P. Correa-Baena, M. K. Nazeeruddin, S. M. Zakeeruddin, W. Tress, A. Abate, A. Hagfeldt and M. Gratzel, Energy Environ. Sci., 2016, 9, 1989-1997.

20 W.-J. Yin, T. Shi and Y. Yan, Appl. Phys. Lett., 2014, 104, 063903.

21 I. Zarazua, G. Han, P. P. Boix, S. Mhaisalkar, F. Fabregat-Santiago, I. Mora-Seró, J. Bisquert and G. Garcia-Belmonte, J. Phys. Chem. Lett., 2016, 7, 5105-5113.

22 I. Zarazua, J. Bisquert and G. Garcia-Belmonte, J. Phys. Chem. Lett., 2016, 7, 525-528.

23 P. Schulz, D. Cahen and A. Kahn, Chem. Rev., 2019, acs.chemrev.8b00558.

24 K. Wojciechowski, T. Leijtens, S. Siprova, C. Schlueter, M. T. Hörantner, J. T.-W. Wang, C.-Z. Li, A. K. Y. Jen, T.-L. Lee and H. J. Snaith, J. Phys. Chem. Lett., 2015, 6, 23992405.

25 Z. Wang, D. P. McMeekin, N. Sakai, S. van Reenen, K. Wojciechowski, J. B. Patel, M. B. Johnston and H. J. Snaith, Adv. Mater., 2017, 29, 1604186.

26 D. Yang, X. Zhou, R. Yang, Z. Yang, W. Yu, X. Wang, C. Li, S. (Frank) Liu and R. P. H. Chang, Energy Environ. Sci., 2016, 9, 3071-3078.

27 E. H. Anaraki, A. Kermanpur, L. Steier, K. Domanski, T. Matsui, W. Tress, M. Saliba, A. Abate, M. Gratzel, A. Hagfeldt and J.-P. Correa-Baena, Energy Environ. Sci., 2016, 9, 3128-3134. 
P. Schulz, ACS Energy Lett., 2018, 3, 1287-1293.

29 I. L. Braly, D. W. deQuilettes, L. M. Pazos-Outón, S. Burke, M. E. Ziffer, D. S. Ginger and H. W. Hillhouse, Nat. Photonics, 2018, 12, 355-361.

30 Y. Hou, Z. R. Zhou, T. Y. Wen, H. W. Qiao, Z. Q. Lin, B. Ge and H. G. Yang, Nanoscale Horizons, 2019, 4, 208-213.

31 D. W. de Quilettes, S. M. Vorpahl, S. D. Stranks, H. Nagaoka, G. E. Eperon, M. E. Ziffer, H. J. Snaith and D. S. Ginger, Science, 2015, 348, 683-686.

32 R. Naphade, B. Zhao, J. M. Richter, E. Booker, S. Krishnamurthy, R. H. Friend, A. Sadhanala and S. Ogale, Adv. Mater. Interfaces, 2017, 4, 1700562.

33 X. Zheng, B. Chen, J. Dai, Y. Fang, Y. Bai, Y. Lin, H. Wei, X. C. Zeng and J. Huang, Nat. Energy, 2017, 2, 17102.

34 J. P. Correa Baena, L. Steier, W. Tress, M. Saliba, S. Neutzner, T. Matsui, F. Giordano, T. J. Jacobsson, A. R. Srimath Kandada, S. M. Zakeeruddin, A. Petrozza, A. Abate, M. K. Nazeeruddin, M. Gratzel and A. Hagfeldt, Energy Environ. Sci., 2015, 8, 2928-2934.

35 S. Chen, Y. Hou, H. Chen, M. Richter, F. Guo, S. Kahmann, X. Tang, T. Stubhan, H. Zhang, N. Li, N. Gasparini, C. O. R. Quiroz, L. S. Khanzada, G. J. Matt, A. Osvet and C. J. Brabec, Adv. Energy Mater., 2016, 6, 1600132-n/a.

36 S. Ryu, J. H. Noh, N. J. Jeon, Y. Chan Kim, W. S. Yang, J. Seo and S. Il Seok, Energy Environ. Sci., 2014, 7, 2614-2618.

37 Q. Wang, Q. Dong, T. Li, A. Gruverman and J. Huang, Adv. Mater., 2016, 28, 6734-6739.

38 M. Stolterfoht, C. M. Wolff, J. A. Márquez, S. Zhang, C. J. Hages, D. Rothhardt, S. 
Albrecht, P. L. Burn, P. Meredith, T. Unold and D. Neher, Nat. Energy, 2018, 3, 847-854.

K. A. Bush, A. F. Palmstrom, Z. J. Yu, M. Boccard, R. Cheacharoen, J. P. Mailoa, D. P.

McMeekin, R. L. Z. Hoye, C. D. Bailie, T. Leijtens, I. M. Peters, M. C. Minichetti, N.

Rolston, R. Prasanna, S. Sofia, D. Harwood, W. Ma, F. Moghadam, H. J. Snaith, T.

Buonassisi, Z. C. Holman, S. F. Bent and M. D. McGehee, Nat. Energy, 2017, 2, 17009.

40 F. Pulvirenti, B. Wegner, N. K. Noel, G. Mazzotta, R. Hill, J. B. Patel, L. M. Herz, M. B.

Johnston, M. K. Riede, H. J. Snaith, N. Koch, S. Barlow and S. R. Marder, Mol. Syst. Des. Eng., , DOI:10.1039/C8ME00031J.

41 A. Pellaroque, N. K. Noel, S. N. Habisreutinger, Y. Zhang, S. Barlow, S. R. Marder and H. J. Snaith, ACS Energy Lett., 2017, 2, 2044-2050.

42 S. N. Habisreutinger, N. K. Noel, H. J. Snaith and R. J. Nicholas, Adv. Energy Mater, 2016, 7, 1601079.

43 M. T. Klug, A. Osherov, A. A. Haghighirad, S. D. Stranks, P. R. Brown, S. Bai, J. T. W. Wang, X. Dang, V. Bulovic, H. J. Snaith and A. M. Belcher, Energy Environ. Sci., 2017, 10, 236-246.

44 J. T.-W. Wang, Z. Wang, S. Pathak, W. Zhang, D. W. deQuilettes, F. Wisnivesky-RoccaRivarola, J. Huang, P. K. Nayak, J. B. Patel, H. A. Mohd Yusof, Y. Vaynzof, R. Zhu, I. Ramirez, J. Zhang, C. Ducati, C. Grovenor, M. B. Johnston, D. S. Ginger, R. J. Nicholas and H. J. Snaith, Energy Environ. Sci., 2016, 9, 2892-2901.

45 P. K. Nayak, M. Sendner, B. Wenger, Z. Wang, K. Sharma, A. J. Ramadan, R. Lovrinčić, A. Pucci, P. K. Madhu and H. J. Snaith, J. Am. Chem. Soc., 2018, 140, 574-577. 
46 D. Pérez-del-Rey, D. Forgács, E. M. Hutter, T. J. Savenije, D. Nordlund, P. Schulz, J. J. Berry, M. Sessolo and H. J. Bolink, Adv. Mater., 2016, 28, 9839-9845.

47 C. F. J. Lau, M. Zhang, X. Deng, J. Zheng, J. Bing, Q. Ma, J. Kim, L. Hu, M. A. Green, S. Huang and A. Ho-Baillie, ACS Energy Lett., 2017, 2, 2319-2325.

48 S. Olthof and K. Meerholz, Sci. Rep., 2017, 7, 40267.

49 J. Emara, T. Schnier, N. Pourdavoud, T. Riedl, K. Meerholz and S. Olthof, Adv. Mater., 2016, 28, 553-559.

50 P. Cui, D. Wei, J. Ji, H. Huang, E. Jia, S. Dou, T. Wang, W. Wang and M. Li, Nat. Energy, 2019, 4, 150-159.

51 P. Calado and P. R. F. Barnes, eprint arXiv:1905.11892, 2019, arXiv:1905.11892.

52 D. Ramirez, K. Schutt, J. F. Montoya, S. Mesa, J. Lim, H. J. Snaith and F. Jaramillo, J. Phys. Chem. C, 2018, 122, 21239-21247.

53 J. Endres, M. Kulbak, L. Zhao, B. P. Rand, D. Cahen, G. Hodes and A. Kahn, J. Appl. Phys., 2017, 121, 35304.

54 M. I. Saidaminov, A. L. Abdelhady, B. Murali, E. Alarousu, V. M. Burlakov, W. Peng, I. Dursun, L. Wang, Y. He, G. Maculan, A. Goriely, T. Wu, O. F. Mohammed and O. M. Bakr, Nat. Commun., 2015, 6, 7586.

55 Y. Liu, Z. Yang, D. Cui, X. Ren, J. Sun, X. Liu, J. Zhang, Q. Wei, H. Fan, F. Yu, X. Zhang, C. Zhao and S. (Frank) Liu, Adv. Mater., 2015, 27, 5176-5183.

56 P. K. Nayak, D. T. Moore, B. Wenger, S. Nayak, A. A. Haghighirad, A. Fineberg, N. K. Noel, O. G. Reid, G. Rumbles, P. Kukura, K. A. Vincent and H. J. Snaith, Nat. Commun., 
2016, 7, 13303.

57 A. Dai, Y. Zhou, A. L. Shu, S. K. Mohapatra, H. Wang, C. Fuentes-Hernandez, Y. Zhang, S. Barlow, Y.-L. Loo, S. R. Marder, B. Kippelen and A. Kahn, Adv. Funct. Mater., 2013, 24, 2197-2204.

58 S. D. Stranks, V. M. Burlakov, T. Leijtens, J. M. Ball, A. Goriely and H. J. Snaith, Phys. Rev. Appl., 2014, 2, 34007.

59 D. W. deQuilettes, S. Jariwala, S. Burke, M. E. Ziffer, J. T.-W. Wang, H. J. Snaith and D. S. Ginger, ACS Nano, 2017, 11, 11488-11496.

60 S. van Reenen, M. Kemerink and H. J. Snaith, J. Phys. Chem. Lett., 2015, 6, 3808-3814.

61 S. N. Habisreutinger, B. Wenger, H. J. Snaith and R. J. Nicholas, ACS Energy Lett., 2017, 2, 622-628.

62 S. N. Habisreutinger, N. K. Noel and H. J. Snaith, ACS Energy Lett., 2018, 3, 2472-2476.

63 H. J. Snaith, A. Abate, J. M. Ball, G. E. Eperon, T. Leijtens, N. K. Noel, S. D. Stranks, J. T.-W. Wang, K. Wojciechowski and W. Zhang, J. Phys. Chem. Lett., 2014, 1511-1515.

64 J. Zhang, T. Zhang, L. Jiang, U. Bach and Y.-B. Cheng, ACS Energy Lett., 2018, 3, $1677-$ 1682.

65 J. P. Bastos, U. W. Paetzold, R. Gehlhaar, W. Qiu, D. Cheyns, S. Surana, V. Spampinato, T. Aernouts and J. Poortmans, Adv. Energy Mater., 2018, 8, 1800554.

66 A. Magomedov, E. Kasparavičius, K. Rakstys, S. Paek, N. Gasilova, K. Genevičius, G. Juška, T. Malinauskas, M. K. Nazeeruddin and V. Getautis, J. Mater. Chem. C, 2018, 6, 8874-8878. 
